Open

\title{
Safety of Eluxadoline in Patients with Irritable Bowel Syndrome with Diarrhea
}

Brooks D. Cash, MD¹, Brian E. Lacy, MD, PhD², Philip S. Schoenfeld, MD³, Leonard S. Dove, PhD ${ }^{4}$ and Paul S. Covington, MD

OBJECTIVES: $\quad$ Eluxadoline is a mixed $\mu$-opioid receptor (OR) and $\kappa-O R$ agonist and $\delta$-OR antagonist, approved for the treatment of irritable bowel syndrome with diarrhea (IBS-D). This analysis evaluated the safety and tolerability of eluxadoline 75 and $100 \mathrm{mg}$ twice daily (BID) in one Phase 2 (IBS-2001) and two Phase 3 (IBS-3001 and IBS-3002) studies.

METHODS: $\quad$ Adults with IBS-D (Rome III criteria) were randomized to placebo or eluxadoline (75 or $100 \mathrm{mg}$ ) BID for 12 (IBS-2001), 26 (IBS-3002), or 52 (IBS-3001) weeks. Safety data were pooled. Adverse events (AEs) were assessed, with special focus on opioid-related AEs, including suspected sphincter of Oddi spasm (SOS) events.

RESULTS: $\quad 2,776$ patients were included in the enrolled set; the safety set comprised 2,814 patients, based on actual treatments received. The most frequent AEs in the placebo and eluxadoline 75 and $100 \mathrm{mg}$ groups were constipation $(2.5,7.4$, and $8.1 \%$, respectively) and nausea $(5.0,8.1$, and $7.1 \%$, respectively); discontinuation due to constipation was uncommon $(0.3,1.1$, and $1.5 \%$, respectively). Ten SOS events $(10 / 1,839 ; 0.5 \%)$ occurred in eluxadoline-treated patients, manifesting as acute abdominal pain with elevated aminotransferases or lipase, or pancreatitis; all occurred in patients without a gallbladder. Eight of these events occurred with the higher dose of eluxadoline, within 1 week of initiation of therapy, and all resolved with eluxadoline discontinuation. There were five events independently adjudicated as pancreatitis not associated with SOS, three of which were associated with heavy alcohol use.

CONCLUSIONS: Eluxadoline was well tolerated in Phase 2 and 3 trials, with constipation and nausea the most common AEs. Consistent with the known adverse effects of opioid agonists, clinically apparent SOS events were observed in eluxadoline-treated patients. All occurred in patients without a gallbladder and the majority were observed in patients on the higher dose of eluxadoline, suggesting a possible association.

SUPPLEMENTARY MATERIAL is linked to the online version of the paper at http://www.nature.com/ajg

Am J Gastroenterol 2017; 112:365-374; doi:10.1038/ajg.2016.542; published online 6 December 2016

\section{INTRODUCTION}

Irritable bowel syndrome (IBS) is a chronic functional gastrointestinal (GI) disorder characterized by recurrent abdominal pain or discomfort and altered bowel movements in the absence of structural, inflammatory, or biochemical abnormalities (1). IBS global prevalence ranges from $\sim 5$ to $15 \%(2-4)$ and approximately one-third of all cases meet criteria for IBS with diarrhea (IBS-D) $(3,5)$. IBS-D is associated with impaired quality of life (6) as well as a marked socioeconomic impact through increased use of health-related resources and reduced work productivity (7-10).

Dietary and lifestyle changes often comprise first-line management strategies for patients with IBS-D (1), although the durability of these interventions remains unproven. Approved pharmacologic therapies for IBS-D include alosetron, a serotonin antagonist used for the treatment of severe IBS-D in women who have not responded to conventional therapy (11), and rifaximin, a nonsystemic antibiotic (12). Both alosetron $(13,14)$ and rifaximin (15)

'Department of Medicine, University of South Alabama, Mobile, Alabama, USA; ${ }^{2}$ Dartmouth-Hitchcock Medical Center, Lebanon, New Hampshire, USA; ${ }^{3}$ University of Michigan School of Medicine, Ann Arbor, Michigan, USA; ${ }^{4}$ Furiex Pharmaceuticals, Inc., an affiliate of Allergan plc, Parsippany, New Jersey, USA. Correspondence: Brooks D. Cash, MD, Department of Medicine, University of South Alabama, 6000 University Commons, 75 University Boulevard, Mobile, Alabama 36688, USA. E-mail: bcash@health.southalabama.edu

Received 22 June 2016; accepted 13 October 2016 
have demonstrated improvement in global IBS symptoms and abdominal pain.

Loperamide, an over-the-counter $\mu$-opioid receptor (OR) agonist, is an effective antidiarrheal agent commonly used to manage the disturbed defecation of IBS-D, although evidence to support its use is minimal (16). In addition, loperamide is well known to precipitate constipation to the point that is has been used in animal and human models to reliably produce constipation $(17,18)$, consistent with the effects of unopposed agonism of the $\mu$-OR (19).

Eluxadoline is a peripherally active, mixed $\mu-\mathrm{OR}$ and $\kappa-\mathrm{OR}$ agonist and $\delta$-OR antagonist (20) that was recently approved by the US Food and Drug Administration for the treatment of IBS-D in adults. Enteric neurons in the GI tract express $\mu-, \delta$-, and $\kappa$-ORs, which regulate GI motility and visceral sensation (21). Although there is potential for the mixed pharmacological profile of eluxadoline (local agonistic targeting of $\mu$ - and $\kappa$-ORs) to be associated with the known class effects of $\mu$-OR agonists, the likelihood of these effects may be reduced through simultaneous $\mu$-/ $\delta$-OR binding (20).

The efficacy of eluxadoline was initially evaluated in a doseranging Phase 2 study (IBS-2001) that demonstrated that eluxadoline $100 \mathrm{mg}$ twice daily (BID) could simultaneously improve abdominal pain and stool consistency over the full 12-week duration of the study (22). Subsequently, two large Phase 3 trials (IBS3001 and IBS-3002) demonstrated the efficacy of eluxadoline in patients with IBS-D (23).

Herein we report the pooled safety and tolerability data from the Phase 2 and 3 clinical studies for the approved doses of eluxadoline, 75 and $100 \mathrm{mg}$.

\section{METHODS}

The Phase 2 (IBS-2001; ClinicalTrial.govidentifier:NCT01130272) and Phase 3 (IBS-3001 and IBS-3002; NCT01553591 and NCT01553747, respectively) studies described herein were conducted with the approval of each investigator's institutional review board or independent ethics committee, and the studies were conducted in accordance with the principles of Good Clinical Practice guidelines. All patients provided written informed consent.

\section{Phase 2 trial}

IBS-2001 was a randomized, double-blind, parallel-group, placebo-controlled study conducted at 263 primary and tertiary care centers in the US, the design and results of which have been previously reported (22). Patients were randomized to receive eluxadoline $(5,25,100$, or $200 \mathrm{mg}$ ) or placebo BID for 12 weeks. Key eligibility criteria were: males and females aged 18-65 years, with a diagnosis of IBS-D (Rome III criteria (24)), a mean daily worst abdominal pain score of $\geq 3.0$ (on a numerical rating scale of 0 (no pain) to 10 (worst pain imaginable)), and a mean daily stool consistency score of $\geq 5.5$ on the Bristol Stool Form Scale (BSFS; scale of 1 (hard, lumpy stools) to 7 (watery, liquid stools)). Patients with a history of inflammatory bowel disease, celiac disease, intestinal obstruction, or evidence of significant hepatic, vascular, or renal disease, were excluded.

\section{Phase 3 trials}

IBS-3001 and IBS-3002 were randomized, double-blind, placebocontrolled, parallel-group, multicenter studies conducted across 556 centers in the US, Canada, and the UK (23). In both trials, patients were randomized to receive eluxadoline ( 75 or $100 \mathrm{mg}$ ) or placebo BID for 52 weeks in IBS-3001 and 26 weeks in IBS3002 . Key inclusion criteria were: patients $18-80$ years of age with IBS-D (Rome III criteria (24)), with an average worst abdominal pain score of $>3.0$, an average BSFS score of $\geq 5.5, \geq 5$ days with a BSFS score of $\geq 5$, and an average IBS-D global symptom score of $\geq 2.0$ (scale of 0 (no symptoms) to 4 (very severe symptoms)). Key exclusion criteria were: a history of inflammatory bowel disease, celiac disease, or alcoholism; abnormal thyroid function; pancreatitis, sphincter of Oddi (SO) dysfunction, or post-cholecystectomy biliary pain; and cholecystitis within the previous 6 months.

\section{Safety assessments}

The safety and tolerability of eluxadoline were evaluated in each of these Phase 2 and Phase 3 studies, and safety assessments included adverse event (AE) reporting, clinical laboratory results, 12-lead electrocardiograms, vital signs, and physical examinations. Concomitant medication use was collected throughout the study.

Special focus was directed on AEs related to the opioid pharmacologic class, including constipation and SO spasm (SOS). In addition to traditional $\mathrm{AE}$ reporting, constipation was also evaluated retrospectively based on patient electronic diary (interactive voice response system) entries. Diary-confirmed constipation as prospectively defined in the protocol was confirmed retrospectively using two of the electronic diary measurements: BSFS score and number of bowel movements. Constipation using the BSFS score was defined as an average score $<2$ over any study week. Constipation using the number of bowel movements was defined as zero bowel movements for $\geq 4$ consecutive days.

As the known class effects of $\mu$-OR agonists on the SO can be difficult to diagnose (25), a safety-focused adjudication committee comprising three independent experts (the Hepatobiliary and Pancreatitis Adjudication Committee) was established outside of the Phase 3 study protocol in order to evaluate suspected pancreatitis and SOS events. For all cases adjudicated, the committee reviewed a treatment-blinded dossier of primary medical records, laboratory reports, radiology reports, and case narratives to determine whether the events met pre-specified case definitions for acute pancreatitis of any etiology or an acute hepatobiliary event, and whether SOS was the precipitating etiology based on a decision algorithm (Supplementary Figure S1).

The committee used the Atlanta criteria for the diagnosis of acute pancreatitis (26), clinically defined as having at least two of the three following features: abdominal pain suggestive of pancreatitis (epigastric pain often radiating to the back), with the start of such pain considered to be the onset of acute pancreatitis; serum amylase or lipase levels three or more times normal; and characteristic findings on computerized tomography, magnetic resonance imaging, or transabdominal ultrasonographic studies. An acute hepatobiliary event of acute abdominal pain with elevated aminotransferases was defined as consisting of all three of the following 
criteria: abdominal pain suggestive of biliary origin (epigastric or right upper quadrant pain), with the start of such pain considered to be the onset of the acute hepatobiliary event; serum alanine transaminase (ALT) or aspartate transaminase levels three or more times normal, or two times an elevated baseline value (if that value was $>3 \times$ upper limit of normal (ULN)); and an event leading to study drug withdrawal. In determining whether a pancreatitis or acute hepatobiliary event had SOS as a precipitating etiology, the committee assessed whether the event was consistent with an acute, reversible pancreatic, or biliary tract obstruction (Supplementary Figure S1).

\section{Data pooling and statistical analysis}

Data for patients receiving eluxadoline or placebo were pooled from IBS-2001, IBS-3001, and IBS-3002. The safety set included all patients who received at least 1 dose of study drug (eluxadoline or placebo), and were the basis for $\mathrm{AE}$ rates. A number of patients from the Phase 3 studies underwent treatment misallocation during the studies. For these patients, the period during which they received the misallocated treatment was determined and safety findings from those "affected days" were summarized based on actual treatments received, irrespective of treatment randomization.
Continuous data were summarized descriptively by number, mean, standard deviation, minimum, median, and maximum. Categorical data were summarized descriptively by frequency. No inferential statistics were performed for safety data.

Safety analyses were also performed using pooled data for the following subgroups: gender, age ( $<65, \geq 65$ years), race, body mass index (BMI; $<30, \geq 30$ ), prior cholecystectomy status, and hepatic dysfunction (based on presence of elevated baseline ALT and elevated baseline total bilirubin).

\section{RESULTS}

Patient demographics, baseline characteristics, and exposure The enrolled set included a total of 2,776 patients across the placebo $(n=981)$, eluxadoline $75 \mathrm{mg}(n=810)$, and eluxadoline $100 \mathrm{mg}(n=985)$ groups (Supplementary Table S1). The mean age was similar across all treatment groups (Table 1). Approximately two-thirds of patients in each treatment group were female and the majority of patients were of white ethnicity. Additional baseline characteristics, including cholecystectomy history and renal and hepatic dysfunction, remained balanced across the treatment groups in the pooled set (Table 1). In both males and females, the overall duration of exposure to randomized eluxadoline

Table 1. Patient demographics and baseline characteristics: pooled analysis for eluxadoline Phase 2 and 3 studies (enrolled set)

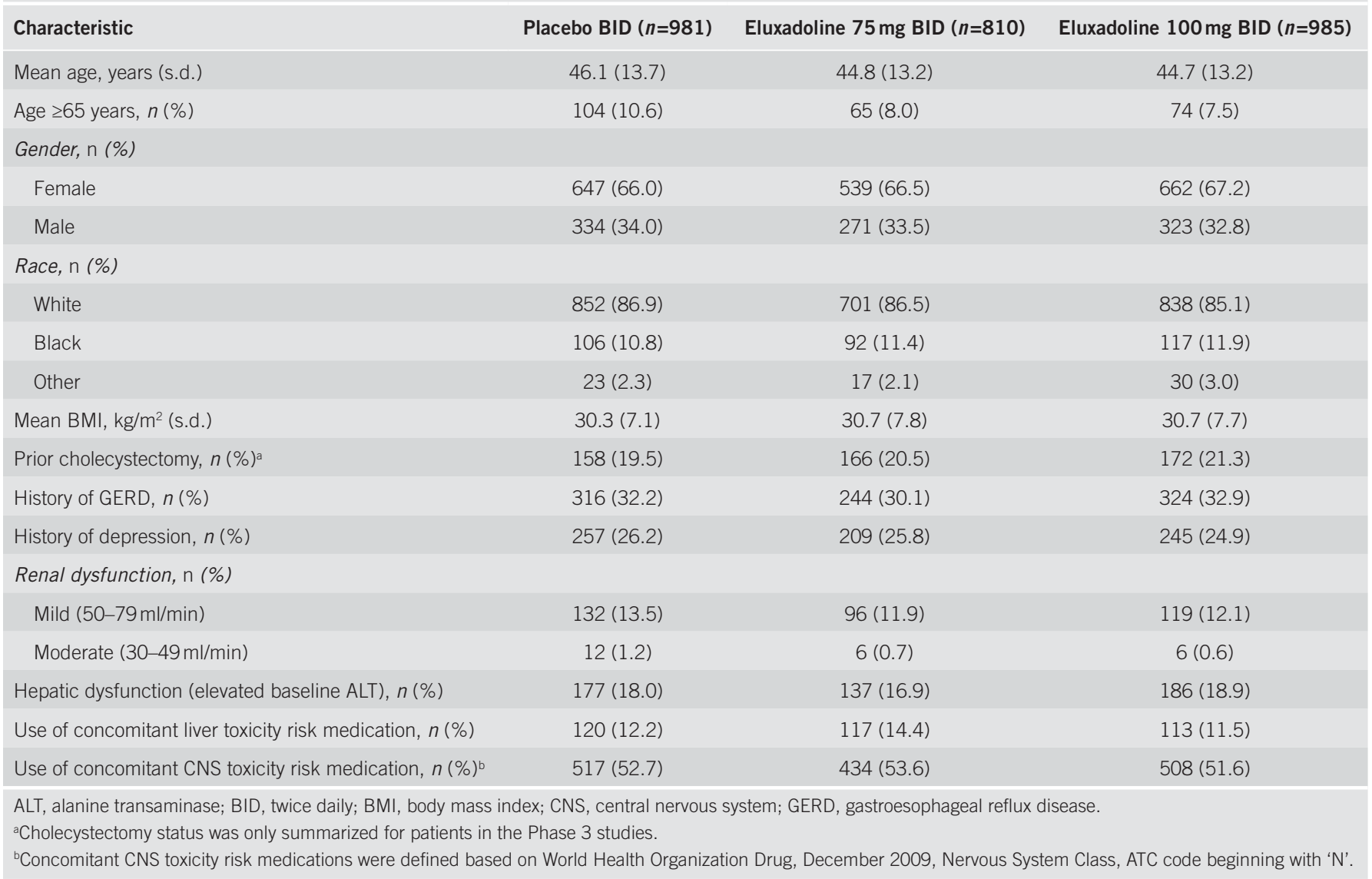


treatment was approximately 26 days longer in the eluxadoline $75 \mathrm{mg}$ group compared with the eluxadoline $100 \mathrm{mg}$ group $(219.7$ vs. 192.4 days, respectively, in males, and 207.9 vs. 182.9 days, respectively, in females; Supplementary Table S2).

\section{AEs}

AEs were summarized for the safety set. After adjustment for treatment misallocation, the number of patients included in the safety set was 2,814 across the placebo ( $n=974)$, eluxadoline $75 \mathrm{mg}$ $(n=807)$, and eluxadoline $100 \mathrm{mg}(n=1032)$ groups (Supplementary Table S1). Over half of the patients in each treatment group reported at least one AE (Table 2). The proportions of patients with any AE leading to discontinuation were higher in patients receiving eluxadoline compared with those receiving placebo, but were similar between eluxadoline doses $(8.3$ and $7.8 \%$ for the 75 and $100 \mathrm{mg}$ groups, respectively, vs. $4.3 \%$ for placebo; Table 2). Constipation and abdominal pain events leading to discontinuation were most commonly reported in eluxadoline-treated patients, but were infrequent (constipation: 1.1 and $1.5 \%$ for eluxadoline 75 and $100 \mathrm{mg}$, respectively; abdominal pain: $1.1 \%$ at both dose levels).

The most common AEs (occurring in $\geq 2 \%$ of patients in any treatment group) reported in eluxadoline-treated patients were constipation, nausea, upper respiratory tract infection, abdominal pain, headache, and vomiting, which tended to occur more frequently compared with patients receiving placebo (Table 2). The overall frequency of constipation AEs was low, with a similar incidence identified between the eluxadoline $75 \mathrm{mg}$ (7.4\% (60/807)) and $100 \mathrm{mg}(8.1 \%(84 / 1,032))$ groups, with lower incidence in the placebo group (2.5\% (24/975); Table 2).

Investigator-reported AEs of increased ALT occurred in 2.1 and $2.5 \%$ of patients for the eluxadoline 75 and $100 \mathrm{mg}$ groups, respectively, compared with the placebo reported rate of $1.4 \%$ (Table 2). Post-randomization ALT elevations $>3 \times$ ULN were rare and the incidence of these events was similar across all treatment groups (Supplementary Table S3). Four eluxadoline-treated patients $(0.2 \%[4 / 1,839])$ had an ALT value $>10-20 \times$ ULN; three receiving eluxadoline $100 \mathrm{mg}(0.3 \%$ [3/1,032]) and one receiving $75 \mathrm{mg}$ $(0.1 \%$ [1/807]; Supplementary Table S3). Another patient receiving eluxadoline $75 \mathrm{mg}$ had an ALT value $>20 \times \operatorname{ULN}(0.1 \%$ [1/807]). Among the five patients with ALT $>10 \times \mathrm{ULN}$, three had findings adjudicated as consistent with SOS, and one was determined to be a specimen error. The remaining patient was a 28 -year-old female randomized to eluxadoline $75 \mathrm{mg}$ (study IBS-3001), who was noted to have asymptomatic elevated ALT at week 18, peaking at $>20 \times$ ULN around week 26 , and resolving $\sim 4$ weeks after study withdrawal. Her prior medical history was notable for obesity (BMI $\left.34.3 \mathrm{~kg} / \mathrm{m}^{2}\right)$, cholecystectomy (5 years previously), and intermittent right upper quadrant discomfort. Additional laboratory and radiological evaluation was notable for hepatomegaly consistent with non-alcoholic fatty liver disease and a relationship to drug could not be excluded. In the pooled Phase 3 studies, the frequency of ALT elevations $>3 \times$ ULN was slightly higher in patients without a gallbladder, irrespective of treatment group (Supplementary Table S3). In patients who retained their gallbladder, no differences were seen in ALT elevations $(\geq 3 \times \mathrm{ULN})$ across the three treatment arms (11/650 [1.7\%], 12/642 [1.9\%], and 7/676 [1.0\%] for placebo and eluxadoline 75 and $100 \mathrm{mg}$, respectively; Supplementary Table S3). There were no cases where ALT elevation coincided with elevations of bilirubin $>2 \times$ ULN. No cases were consistent with a Hy's Law case, which has the following three components: (1) hepatocellular injury, shown by a higher incidence of $\geq 3 \times$ ULN of ALT or AST than a non-hepatotoxic control drug or placebo; (2) among trial subjects showing such elevations, one or more also show elevation of serum total bilirubin to $>2 \times$ ULN without initial findings of cholestasis; and (3) no other reason can be found to explain the combination of increased transaminases and total bilirubin (27).

\section{Serious AEs (SAEs)}

The frequency of SAEs was low, and slightly higher in eluxadolinetreated patients (75 mg: 4.2\%; $100 \mathrm{mg}: 4.0 \%$ ) compared with those receiving placebo (2.6\%; Table 2). No deaths were reported during the studies. One patient in study IBS-3001 died 21 days after receiving the last dose of eluxadoline $(75 \mathrm{mg})$, following an SAE (lower-extremity cellulitis) that was not considered drug related.

Pancreatitis was the most commonly reported SAE in eluxadoline-treated patients, although the overall incidence was consistently low (75 mg: $0.4 \%$ [3/807]; $100 \mathrm{mg}: 0.4 \%$ [4/1,032]; overall: $0.4 \%[7 / 1,839]$; Table 3$)$. No SAEs of constipation were reported in any treatment group.

There were six major adverse cardiac events that were evenly distributed between patients randomized to placebo $(0.3 \% ; 3 / 975)$ and eluxadoline $(0.2 \% ; 3 / 1,839$; Table 3$)$. All of these eluxadolinetreated patients were $\geq 70$ years of age and all had medical histories or risk factors for cardiopulmonary disease (23).

In the eluxadoline $100 \mathrm{mg}$ group, there was a single case of suspected colon ischemia in a 72-year-old female with a recent history of polymicrobial sepsis (treated with antibiotics) and chronic medical conditions including type II diabetes mellitus, non-alcoholic hepatic steatosis with cirrhosis, pulmonary hypertension with chronic obstructive pulmonary disease, and diverticulosis. Nineteen days after the first dose of study drug, the patient developed abdominal pain, nausea, and vomiting followed by rectal bleeding and hypotension, with a blood pressure reading of $80 / 40 \mathrm{~mm} \mathrm{Hg}$ documented at home. Concomitant medications at the time of event onset included acetylsalicylic acid, gabapentin, lovastatin, omeprazole, psyllium mucilloid, sertraline, temazepam, and ursodeoxycholic acid. Upon presentation, blood pressure was $147 / 90 \mathrm{~mm} \mathrm{Hg}$ with a heart rate of 93 beats per minute; abdominal examination was unremarkable. Colonoscopy and histologic examinations were consistent with colon ischemia, with biopsy specimens revealing microscopic focus of reparative epithelial changes suggestive of colon ischemia in the ascending colon, and focal epithelial erosion and reparative epithelial changes compatible with colon ischemia in the transverse colon, descending colon, and sigmoid colon: the patient recovered uneventfully and there were no known complications at the time of last follow-up. The patient's electronic diary showed no recordings of constipation prior to the event. 
Table 2. Summary of pooled AEs and SOS and pancreatitis events from Phase 2 and 3 studies (safety set)

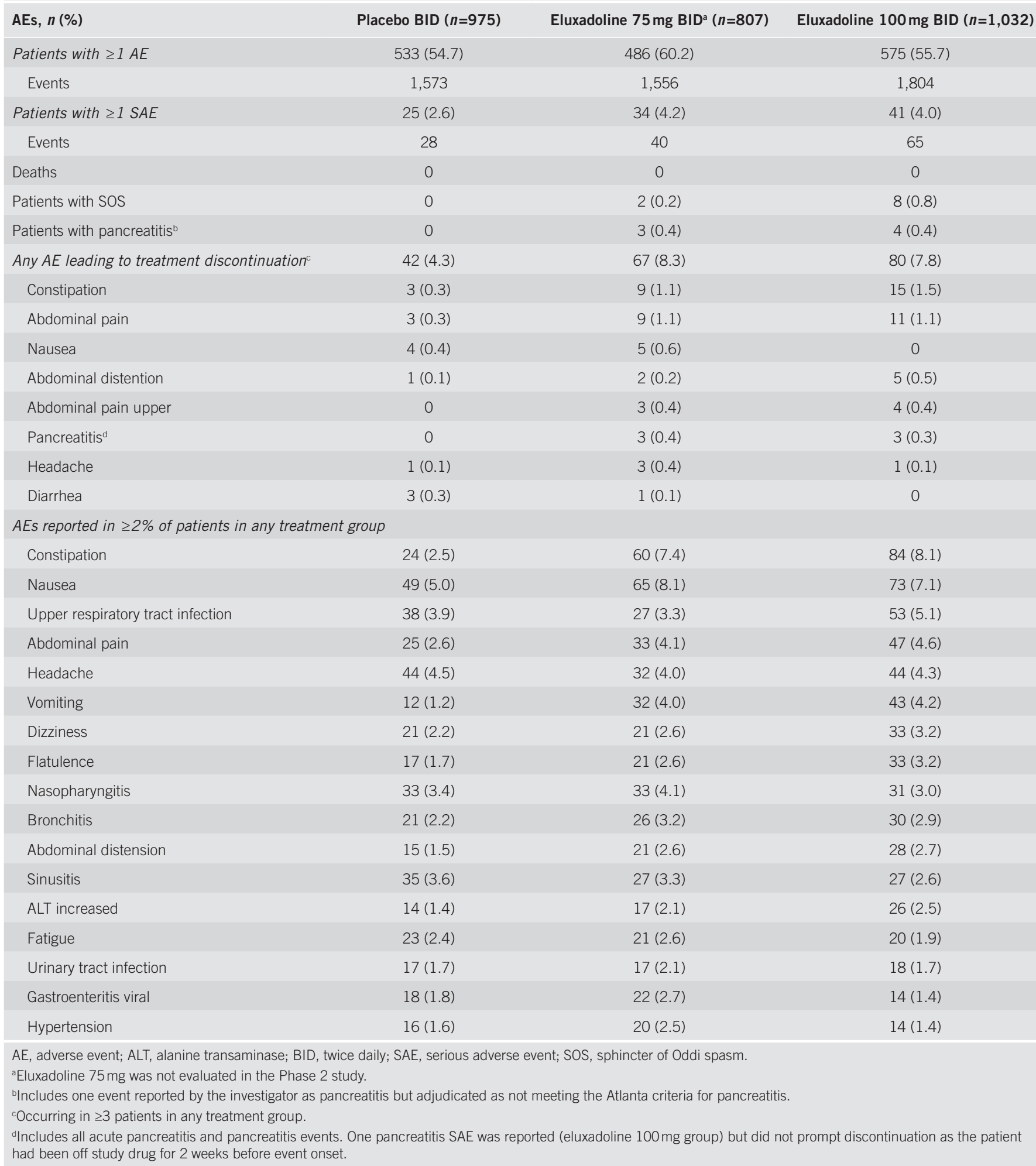

\section{$A E$ and $S A E s$ in patient subpopulations}

The incidence of AEs and SAEs tended to be slightly increased in females compared with males across all treatment groups, except for SAEs in patients receiving eluxadoline $75 \mathrm{mg}$, which was balanced across genders (females: $4.3 \%$; males: $4.1 \%$; Supplementary Table S4). The frequency of AEs leading to treatment 
Table 3. SAEs reported in $\geq 2$ patients treated with eluxadoline 75 or $100 \mathrm{mg}$ or placebo: pooled analysis for eluxadoline Phase 2 and 3 studies (safety set)

\begin{tabular}{|c|c|c|c|}
\hline SAEs, $n(\%)$ & $\begin{array}{l}\text { Placebo BID } \\
(n=975)\end{array}$ & $\begin{array}{l}\text { Eluxadoline } \\
75 \mathrm{mg} \mathrm{BID}{ }^{\mathrm{a}} \\
(n=807)\end{array}$ & $\begin{array}{c}\text { Eluxadoline } \\
100 \mathrm{mg} \text { BID } \\
(n=1,032)\end{array}$ \\
\hline $\begin{array}{l}\text { Major adverse } \\
\text { cardiac events }\end{array}$ & $3(0.3)$ & $1(0.1)$ & $2(0.2)$ \\
\hline Pancreatitis $^{b}$ & 0 & $3(0.4)$ & $4(0.4)$ \\
\hline Abdominal pain & 0 & $1(0.1)$ & $3(0.3)$ \\
\hline Angina pectoris & 0 & $2(0.2)$ & $2(0.2)$ \\
\hline Chest pain & $1(0.1)$ & $2(0.2)$ & $1(0.1)$ \\
\hline $\begin{array}{l}\text { ALT or AST } \\
\text { increased }\end{array}$ & 0 & 0 & $2(0.2)$ \\
\hline Anxiety & $2(0.2)$ & 0 & $2(0.2)$ \\
\hline $\begin{array}{l}\text { Road traffic } \\
\text { accident }\end{array}$ & 0 & $1(0.1)$ & $2(0.2)$ \\
\hline Diverticulitis & 0 & $2(0.2)$ & $1(0.1)$ \\
\hline Osteoarthritis & $1(0.1)$ & $2(0.2)$ & 0 \\
\hline Influenza & 0 & $2(0.2)$ & 0 \\
\hline \multicolumn{4}{|c|}{$\begin{array}{l}\text { ALT, alanine transaminase; AST, aspartate transaminase; BID, twice daily; } \\
\text { SAE, serious adverse event. } \\
\text { aThe eluxadoline } 75 \mathrm{mg} \text { dose was not evaluated in the Phase } 2 \text { study. } \\
\text { bIncludes all acute pancreatitis and pancreatitis events; includes one event } \\
\text { reported by the investigator as pancreatitis but adjudicated as not meeting the } \\
\text { Atlanta criteria for pancreatitis. }\end{array}$} \\
\hline
\end{tabular}

discontinuation, and GI AEs and SAEs, was also slightly higher in females compared with males across all treatment groups.

A similar trend was observed with AEs and SAEs when patients were analyzed according to a cut-off of 65 years of age; slightly more AEs were noted in patients $\geq 65$ years of age compared with those $<65$ years of age across treatment groups (Supplementary Table S4). The incidence of AEs, SAEs, and AEs leading to treatment discontinuation also tended to be slightly increased in white patients compared with black patients across treatment groups (Supplementary Table S4). Patients with a BMI $\geq 30 \mathrm{~kg} / \mathrm{m}^{2}$ had an increased frequency of AEs and SAEs across treatment groups, although the frequency of AEs leading to discontinuation, GI AEs, and GI SAEs was balanced between BMI groups (Supplementary Table S4). Patients without a gallbladder had an increased frequency of all AEs and SAEs, including non-GI-related AEs, across treatment groups (Supplementary Table S4).

\section{AEs and SAEs over time}

For eluxadoline-treated patients, AEs (Figure 1a) and SAEs (Figure 1b) were most often reported within the first 2 weeks of treatment initiation and were more frequently reported than in patients who received placebo. Acute pancreatitis was the most common SAE reported during the first 2 weeks of treatment, occurring in two patients $(0.2 \%[2 / 1,032])$ receiving eluxadoline $100 \mathrm{mg}$. AE incidence was similar across the eluxadoline $(75 \mathrm{mg}$ :
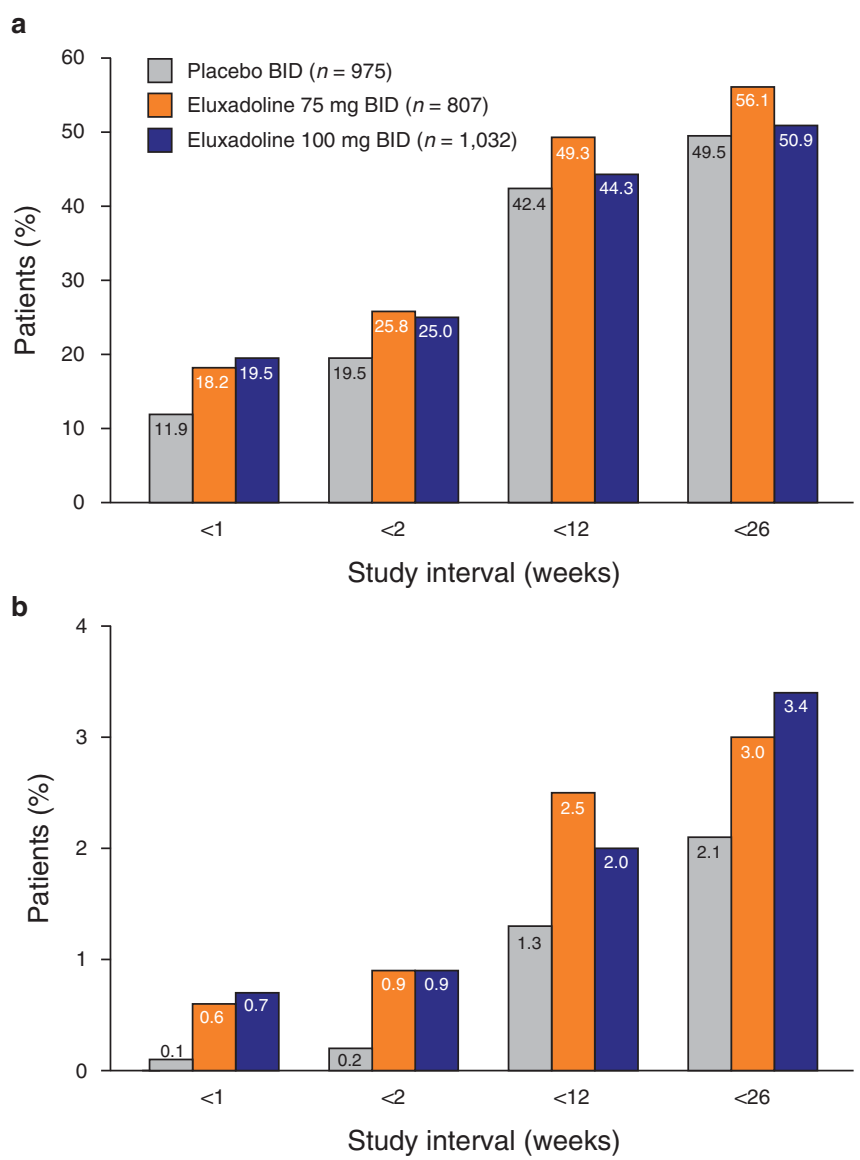

Figure 1. Incidence of (a) AEs and (b) SAEs by time interval: pooled analysis for eluxadoline Phase 2 and 3 studies (safety set). For the Phase 2 study (IBS-2001) events were nominally reported up to the end of treatment visit at week 12 only (and not through the last follow-up visit at week 14), while for the Phase 3 studies events were counted up to the last visit (up to the week 54 visit in IBS-3001 and the week 30 visit in IBS-3002). $A E$, adverse event; BID, twice daily; SAE, serious adverse event.

49.3\% [398/807]; $100 \mathrm{mg}: 44.3 \%$ [457/1,032]) and placebo (42.4\% [413/975]) groups by 12 weeks of treatment (Figure 1a), and SAE incidence was higher in eluxadoline-treated patients (75 mg: 2.5\% [20/807]; $100 \mathrm{mg}: 2.0 \%$ [21/1,032]) compared with placebo (1.3\% [13/975]) at week 12 (Figure 1b). The proportions of patients with AEs (Figure 1a) and SAEs (Figure 1b) remained similar between the treatment groups by the first 26 weeks of treatment, with slightly higher SAE incidence in the eluxadoline $100 \mathrm{mg}$ group.

\section{AEs of special interest: constipation}

The majority of constipation AEs were reported within the first 3 months of treatment initiation (Figure 2). During months 4-12, the incidence of constipation AEs declined to a consistent low level ( $<2 \%$ in any treatment group) and was comparable between treatment groups (Figure 2).

The incidence of diary-confirmed constipation based on a daily score of zero bowel movements for $\geq 4$ consecutive days during the 
first 3 months of treatment was also similar across the eluxadoline 75 and $100 \mathrm{mg}$ and placebo groups $(2.9,3.8$, and $2.6 \%$, respectively). Similar rates of patients with constipation were seen during months 4-6 in the eluxadoline 75 and $100 \mathrm{mg}$ and placebo groups $(2.8,3.6$, and $1.4 \%$, respectively).

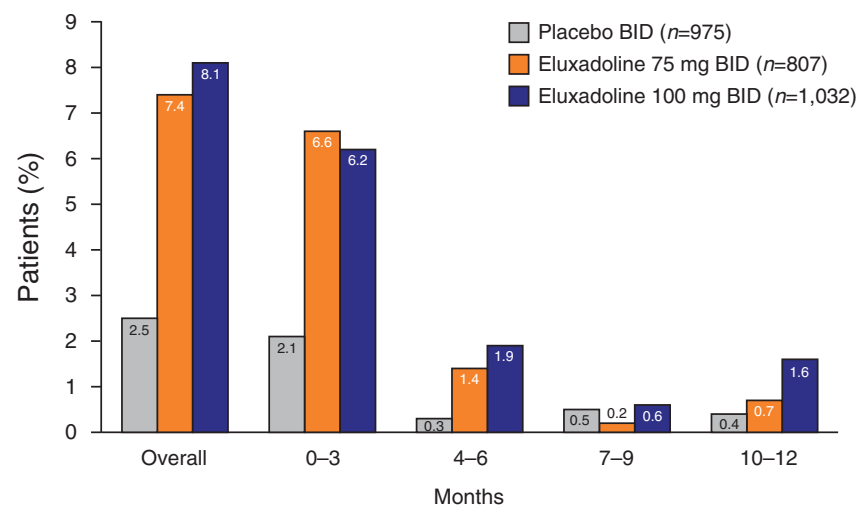

Figure 2. Incidence of constipation AEs by time: ${ }^{a, b}$ pooled analysis for

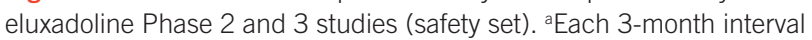
was defined as a 13-week period, starting from the date of the first dose of study drug; 'اncidence was defined as number of patients with at least one constipation event, and for the patient-level summary, multiple occurrences of constipation within a patient are counted once only. All occurrences of constipation were included in the total number of constipation events. Percentages were based on patients being in the study for $\geq 1$ day within a period (overall, each quarter). Patients receiving $>1$ treatment are included in summaries of each treatment. AE, adverse event; BID, twice daily.
Rates of diary-confirmed constipation based on average weekly BSFS scores $<2$ were similar to the rates for spontaneous reports of constipation AEs across the eluxadoline 75 and $100 \mathrm{mg}$ and placebo groups. Across all groups, the percentages of patients with any diary-confirmed constipation event defined by BSFS scores were lowest in the first month, and then remained stable over the remaining months of double-blind treatment.

\section{AEs of special interest: SOS events}

Overall, 10 events $(10 / 1,839 ; 0.5 \%)$ consistent with SOS occurred in patients receiving eluxadoline; two with eluxadoline $75 \mathrm{mg}$ (2/807; $0.2 \%)$ and eight with eluxadoline $100 \mathrm{mg}$ (8/1032; 0.8\%; Tables 2 and 4). Eight presented with abdominal pain and elevated aminotransferases; one in a patient receiving eluxadoline $75 \mathrm{mg}(0.1 \%$ of treatment group [1/807] $)$ and seven in patients receiving eluxadoline $100 \mathrm{mg}$ ( $0.7 \%$ of treatment group [7/1,032]; Table 4). Another SOS event, in a patient receiving eluxadoline $100 \mathrm{mg}$, was adjudicated as consistent with pancreatitis. The remaining SOS event occurred in a patient receiving eluxadoline $75 \mathrm{mg}$ and presented as a mild lipase elevation (1.6×ULN) with abdominal pain; the Adjudication Committee did not believe this met the Atlanta criteria for pancreatitis. All SOS events occurred in patients without a gallbladder (Table 4).

SOS events with elevated aminotransferases were transient and resolved rapidly on treatment discontinuation and $75 \%$ $(6 / 8)$ occurred within 1 week of treatment initiation. All patients presented with either epigastric/abdominal or biliary pain, often with nausea; one patient receiving eluxadoline $100 \mathrm{mg}$ was briefly

Table 4. Summary of SOS and adjudicated pancreatitis events: pooled analysis for eluxadoline Phase 2 and 3 studies

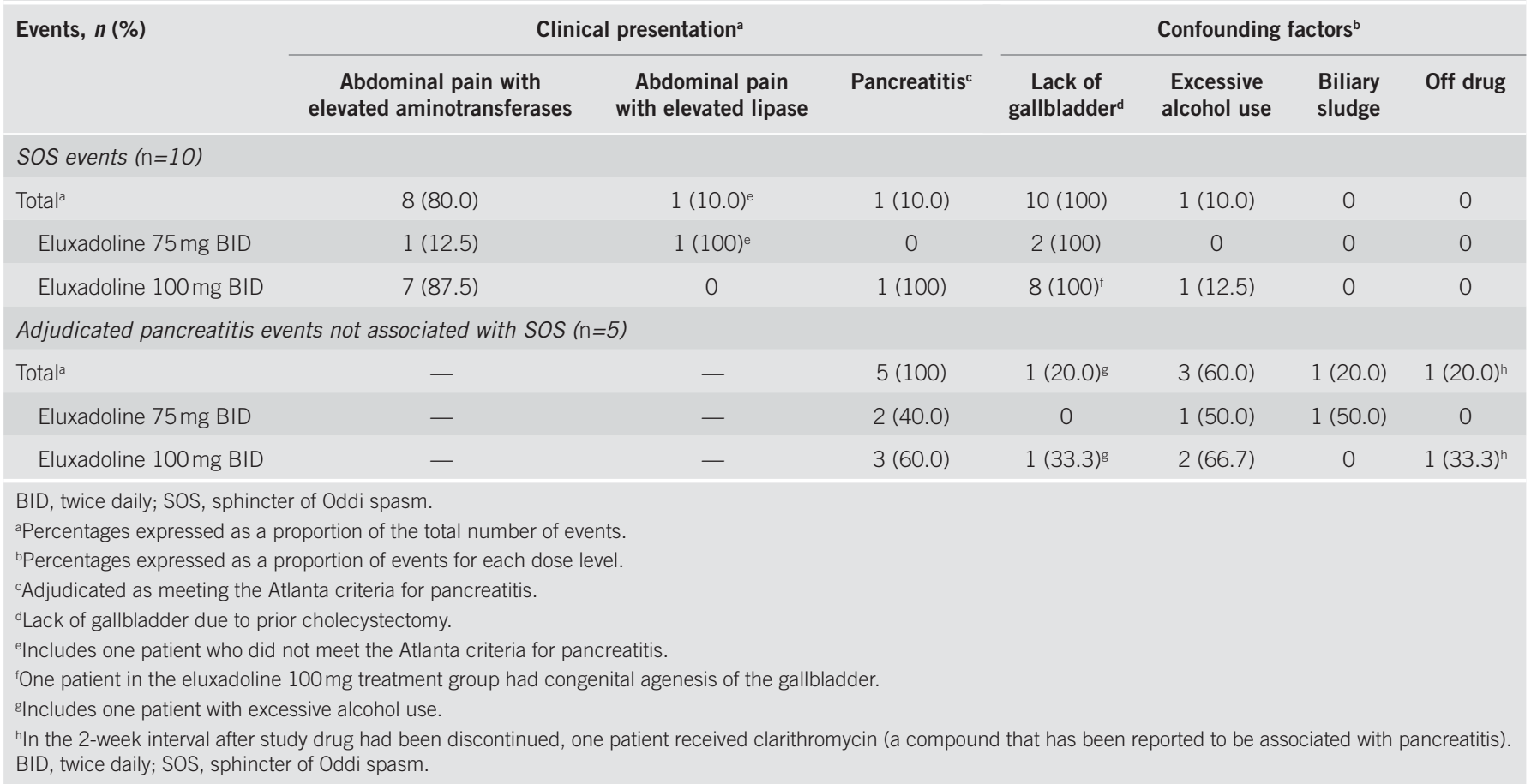


hospitalized to control nausea and vomiting, and the remaining seven were managed as outpatients.

In the patient with adjudicated pancreatitis consistent with SOS, the abdominal pain was mild, transient, occurred within minutes of the first dose, and was adjudicated as probably drug related. The patient was briefly hospitalized with no complications. In the case of SOS associated with mild lipase elevation, the patient presented with nausea and abdominal pain after 2 doses of study drug. Lipase normalized within $24 \mathrm{~h}$ of stopping treatment.

\section{AEs of special interest: pancreatitis}

Including the single event consistent with SOS, seven events were reported as pancreatitis in eluxadoline-treated patients $(0.4 \%$; $7 / 1,839)$; three with eluxadoline $75 \mathrm{mg}(0.4 \% ; 3 / 807)$ and four with eluxadoline $100 \mathrm{mg}(0.4 \%$; 4/1,032; Table 2); six of the seven events were ultimately adjudicated as meeting the Atlanta criteria for pancreatitis (Table 4).

Of the five adjudicated pancreatitis events not consistent with SOS, three were associated with heavy alcohol use (one in the $75 \mathrm{mg}$ group $[1 / 2 ; 50.0 \%]$; two in the $100 \mathrm{mg}$ group $[2 / 3 ; 66.7 \%])$, one was associated with biliary sludge (75 mg group $[1 / 2 ; 50.0 \%]$ ), and one occurred in a patient who had discontinued eluxadoline 2 weeks before the event (100 mg group [1/3; 33.3\%]; Table 4).

The patient with biliary sludge presented with pancreatitis after 26 weeks of treatment and had no history of alcohol use; this patient may therefore have been predisposed to pancreatitis (28), and the event was adjudicated as unlikely to be drug related. The event in the patient who was off drug was also considered unlikely to be drug related due to the time interval and concomitant treatment with clarithromycin during the intervening two weeks.

All cases of pancreatitis were mild as defined by the Atlanta criteria and all patients discontinued treatment at event onset. All cases resolved clinically, with lipase normalization within days, except in one patient with chronic, severe alcoholism (eluxadoline $100 \mathrm{mg}$ group), who improved clinically in 1-2 days, but required several weeks to normalize enzymes.

\section{DISCUSSION}

In this pooled analysis of one Phase 2 and two Phase 3 studies, eluxadoline (75 and $100 \mathrm{mg}$ doses) was well tolerated in patients with IBS-D, with similar incidence rates of AEs and SAEs across treatment groups.

The number of patients reporting at least one AE was balanced across treatment groups. Non-serious GI AEs were the most commonly reported AEs in eluxadoline-treated patients compared with those receiving placebo. Although GI SAEs were the most common SAEs reported in any group, overall incidence was low $(<0.5 \%$ for any treatment group). AEs and SAEs were more frequently reported in females compared with males, possibly reflecting gender differences in IBS-D pathophysiology (29). Similar safety findings, irrespective of treatment group, were observed for patients $>65$ years of age, those with BMI $\geq 30 \mathrm{~kg} / \mathrm{m}^{2}$, and for patients of white ethnicity.
Constipation, while infrequent, was the most common GI AE observed with eluxadoline and most often occurred within 3 months of treatment initiation. Similarly, diary-confirmed constipation events based on scores of zero bowel movements or weekly BSFS scores were uncommon, and comparable across eluxadoline and placebo groups ( $<4 \%$ in each group), with similar rates reported during the first 3 months after treatment initiation and months 4-6. No SAEs of constipation were reported with eluxadoline and discontinuation due to constipation was infrequent.

Agonism of $\mu$-OR and $\kappa$-ORs is known to increase GI muscle tone, reduce GI motility through reduced contraction and peristalsis, and inhibit secretion from enterocytes (30). The role of $\delta$-OR antagonism by eluxadoline remains unclear, although it may functionally oppose the effects of $\mu$-OR agonism (20). The class effects of $\mu$-OR agonists, including loperamide $(31,32)$, are associated with drug-induced acute pancreatitis (31-38) and SOS, through increased SO phasic wave frequency (39-46).

Events consistent with SOS were rare, occurring in $0.5 \%$ of eluxadoline-treated patients, with a higher incidence in the eluxadoline 100 vs. $75 \mathrm{mg}$ group. SOS events most often presented as abdominal pain with elevated aminotransferases and all cases occurred in patients without a gallbladder. Cholecystectomy has been associated with suppression of cholecystokinin-mediated inhibition of SO phasic activity, despite normal bile duct pressure and SO motility compared to the pre-cholecystectomy state (SO phasic wave frequency: 1.6 per minute pre-cholecystectomy vs. 4 per minute post-cholecystectomy) (47). Therefore, eluxadoline's $\mu$-OR agonist activity at the SO may further increase SO tone in these patients, increasing the risk of clinically apparent SOS events. This is supported by the observation that the majority of events adjudicated as consistent with SOS occurred with the $100 \mathrm{mg}$ dose of eluxadoline occurred early after treatment initiation, and all events rapidly resolved upon treatment discontinuation. Therefore, consistent with FDA-approved labeling, patients without a gallbladder treated with eluxadoline should receive the $75 \mathrm{mg}$ dose (48) and be monitored for new or worsening abdominal pain, with or without nausea and vomiting, or acute biliary pain with liver or pancreatic enzyme elevations. Although ALT elevations were substantial in some of the events, the rapidity of symptom onset, associated biliary symptoms, and abrupt rise and recovery suggest that these events were typical of a hepatobiliary spasm/obstructive process rather than drug-induced liver injury $(45,49)$. In the patient with asymptomatic ALT elevation $>20 \times \mathrm{ULN}$, the time to onset of 18-26 weeks was atypical of drug-induced liver toxicity, although a relationship to drug could not be excluded.

Adjudicated pancreatitis events in eluxadoline-treated patients were rare, clinically mild and transient, and occurred in similar proportions of patients treated with eluxadoline $75 \mathrm{or} 100 \mathrm{mg}$. The majority of pancreatitis events not associated with SOS were associated with excessive alcohol consumption and alcohol has been documented to alter pancreatic ductal and periductal anatomy $(50-52)$, and to contribute to increases in SO pressure $(53,54)$. While it is possible that the $\mu$-OR activity of eluxadoline may have increased SO contractility, which was further exacerbated by alcohol use in patients who experienced pancreatitis, determining a 
causal relationship with eluxadoline for these events is difficult. Nevertheless, due to the potential for increased risk of acute pancreatitis in patients with excessive alcohol intake alone, eluxadoline is contraindicated in patients with a history of alcohol abuse or addiction, and in patients with chronic or acute excessive alcohol consumption (48).

The single case of colon ischemia occurred in a patient with multiple comorbidities known to be associated with colon ischemia (including age (72 years), recent polymicrobial sepsis, type II diabetes mellitus, pulmonary hypertension, and concomitant selective serotonin reuptake inhibitor use). A causal association with eluxadoline was felt to be unlikely, given the lack of diary reports of constipation and the lack of evidence supporting a physiologic effect on systemic or GI blood flow with eluxadoline or other poorly absorbed OR-targeting anti-diarrheals (55).

Eluxadoline is an effective treatment option in patients with IBS-D, based on efficacy data from one Phase 2 (ref. 22) and two Phase 3 studies (23). In this pooled safety analysis of those studies, eluxadoline was well tolerated and most treatment-emergent AEs occurred early after initiation of treatment, were not serious, and were not associated with any clinically meaningful sequelae. Constipation AEs were infrequent and discontinuation due to constipation was low. Eluxadoline may increase the risk of SOS in patients without a gallbladder, thus, patients without a gallbladder should be monitored during eluxadoline treatment at the recommended dose of $75 \mathrm{mg}$ BID (48), and the benefits and risks of eluxadoline should be evaluated in the context of IBS-D symptom severity. There may also be potential for increased risk of pancreatitis with eluxadoline, especially associated with heavy alcohol use. Eluxadoline is therefore contraindicated in patients with a history of pancreatitis, structural diseases of the pancreas, known or suspected SO dysfunction, alcoholism, alcohol abuse, alcohol addiction, or excessive alcohol use ( $>3$ alcoholic beverages per day) (48), and patients should avoid chronic or acute excessive alcohol consumption while taking eluxadoline.

\section{ACKNOWLEDGMENTS}

We met criteria for authorship as recommended by the International Committee of Medical Journal Editors. We take full responsibility for the scope, direction, and content of the manuscript and have approved the submitted manuscript. We received no compensation related to the development of the manuscript. We would like to thank Kieran Davey, PhD, and Tanja Torbica, PhD, of Complete HealthVizion, Inc., Chicago, IL, for editorial assistance in the writing and revision of the draft manuscript on the basis of detailed discussion and feedback from all the authors; this assistance was funded by Allergan plc.

\section{CONFLICT OF INTEREST}

Guarantor of the article: Brooks D. Cash, MD.

Specific author contributions: Planning and conducting the study: Leonard S. Dove and Paul S. Covington; Collection and interpretation of data: Brooks D. Cash, Brian E. Lacy, Philip S. Schoenfeld, Leonard S. Dove, and Paul S. Covington; Drafting and revision of the manuscript: Brooks D. Cash, Brian E. Lacy, Philip S. Schoenfeld,
Leonard S. Dove, and Paul S. Covington. All authors approved the final draft of this manuscript for submission.

Potential conflicts of interests: Brooks D. Cash has served as an advisor, consultant, or speaker for Actavis, Inc., a subsidiary of Allergan plc, Salix Pharmaceuticals, Takeda Pharmaceuticals, Prometheus Laboratories, IM HealthScience, and Ironwood Pharmaceuticals. Brian E. Lacy has participated in advisory boards for Ironwood Pharmaceuticals, Prometheus Laboratories, Salix Pharmaceuticals, and Actavis, Inc., a subsidiary of Allergan plc. Philip S. Schoenfeld has served as an advisor, consultant, or speaker for Actavis, Inc., a subsidiary of Allergan plc, Salix Pharmaceuticals, Ironwood Pharmaceuticals, and Synthetic Biologics, and is a partner in MD Evidence. Leonard S. Dove and Paul S. Covington serve as scientific consultants for Allergan plc.

Financial support: These studies were supported by Furiex Pharmaceuticals, Inc., a subsidiary of Allergan plc. The sponsor was responsible for study design and data analysis, in collaboration with all authors. The collection and interpretation of the study data and writing of the manuscript was carried out by the authors.

\section{Study Highlights}

\section{WHAT IS CURRENT KNOWLEDGE}

Irritable bowel syndrome with diarrhea (IBS-D) is a chronic functional gastrointestinal (GI) disorder that affects 5-15\% of people worldwide.

Eluxadoline is a $\mu$ - and $\kappa$-opioid receptor (OR) agonist and $\delta$-OR antagonist recently approved for the treatment of IBS-D.

The opioid pharmacological class is known to be associated with adverse events (AEs) of constipation and sphincter of Oddi spasm (SOS).

$\checkmark$ A full safety evaluation of eluxadoline over the Phase 2 and 3 developmental program has not yet been reported.

\section{WHAT IS NEW HERE}

The most common AEs with eluxadoline are overall infrequent, and include constipation, nausea, and respiratory tract infection.

Constipation leading to treatment discontinuation is uncommon in eluxadoline-treated patients.

$\checkmark$ The incidence of SOS is rare with eluxadoline treatment and tends to occur in patients without a gallbladder.

Eluxadoline may increase the risk of pancreatitis in patients with heavy alcohol use, and is contraindicated in this patient group.

\section{REFERENCES}

1. Chey WD, Kurlander J, Eswaran S. Irritable bowel syndrome: a clinical review. JAMA 2015;313:949-58.

2. Canavan C, West J, Card T. The epidemiology of irritable bowel syndrome. Clin Epidemiol 2014;6:71-80.

3. Lovell RM, Ford AC. Global prevalence of and risk factors for irritable bowel syndrome: a meta-analysis. Clin Gastroenterol Hepatol 2012;10:712-21.

4. Quigley EM, Abdel-Hamid H, Barbara G et al. A global perspective on irritable bowel syndrome: a consensus statement of the World Gastroenterology Organisation Summit Task Force on irritable bowel syndrome. J Clin Gastroenterol 2012;46:356-66. 
5. Su AM, Shih W, Presson AP et al. Characterization of symptoms in irritable bowel syndrome with mixed bowel habit pattern. Neurogastroenterol Motil 2014;26:36-45.

6. Spiegel B, Harris L, Lucak S et al. Developing valid and reliable health utilities in irritable bowel syndrome: results from the IBS PROOF Cohort. Am J Gastroenterol 2009;104:1984-91.

7. Hulisz D. The burden of illness of irritable bowel syndrome: current challenges and hope for the future. J Manag Care Pharm 2004;10:299-309.

8. Paré P, Gray J, Lam S et al. Health-related quality of life, work productivity, and health care resource utilization of subjects with irritable bowel syndrome: baseline results from LOGIC (Longitudinal Outcomes Study of Gastrointestinal Symptoms in Canada), a naturalistic study. Clin Ther 2006;28:1726-35.

9. Everhart JE, Ruhl CE. Burden of digestive diseases in the United States part I: overall and upper gastrointestinal diseases. Gastroenterology 2009;136:376-86

10. Agarwal N, Spiegel BM. The effect of irritable bowel syndrome on healthrelated quality of life and health care expenditures. Gastroenterol Clin North Am 2011;40:11-19.

11. US Food and Drug Administration. Lotronex. Highlights of prescribing information. Available at http://www.accessdata.fda.gov/drugsatfda_docs/ label/2010/021107s016lbl.pdf, 2010. Accessed on 5 May 2015.

12. US Food and Drug Administration. Xifaxan. Highlights of prescribing information. Available at http://www.accessdata.fda.gov/drugsatfda_docs/ label/2015/021361s012lbledt.pdf, 2015. Accessed on 17 July 2015.

13. Camilleri M, Chey WY, Mayer EA et al. A randomized controlled clinical trial of the serotonin type 3 receptor antagonist alosetron in women with diarrheapredominant irritable bowel syndrome. Arch Intern Med 2001;161:1733-40.

14. Lembo T, Wright RA, Bagby B et al. Alosetron controls bowel urgency and provides global symptom improvement in women with diarrhea-predominant irritable bowel syndrome. Am J Gastroenterol 2001;96:2662-70.

15. Pimentel M, Lembo A, Chey WD et al. Rifaximin therapy for patients with irritable bowel syndrome without constipation. N Engl J Med 2011;364: 22-32.

16. Ford AC, Moayyedi P, Lacy BE et al. American College of Gastroenterology monograph on the management of irritable bowel syndrome and chronic idiopathic constipation. Am J Gastroenterol 2014;109(Suppl 1):S2-S26.

17. Marcus SN, Heaton KW. Irritable bowel-type symptoms in spontaneous and induced constipation. Gut 1987;28:156-9.

18. Nassif A, Oswald S, Kühn J-P et al. Loperamide-induced constipation in healthy subjects - an experimental model to evaluate the anti-constipation effect of methylnaltrexone. Br J Clin Pharmacol 2011;72(Suppl.1):23.

19. De Schepper HU, Cremonini F, Park MI et al. Opioids and the gut: pharmacology and current clinical experience. Neurogastroenterol Motil 2004;16:383-94.

20. Wade PR, Palmer JM, McKenney S et al. Modulation of gastrointestinal function by MuDelta, a mixed $\mu$ opioid receptor agonist/ $\mu$ opioid receptor antagonist. Br J Pharmacol 2012;167:1111-25.

21. Holzer P. Opioid receptors in the gastrointestinal tract. Regul Pept 2009;155: 11-17.

22. Dove LS, Lembo A, Randall CW et al. Eluxadoline benefits patients with irritable bowel syndrome with diarrhea in a phase 2 study. Gastroenterology 2013;145:329-38

23. Lembo AJ, Lacy BE, Zuckerman MJ et al. Eluxadoline for irritable bowel syndrome with diarrhea. N Engl J Med 2016;374:242-53.

24. Drossman DA. The functional gastrointestinal disorders and the Rome III process. Gastroenterology 2006;130:1377-90.

25. Yaghoobi M, Romagnuolo J. Sphincter of Oddi dysfunction: updates from the recent literature. Curr Gastroenterol Rep 2015;17:31.

26. Banks PA, Bollen TL, Dervenis C et al. Classification of acute pancreatitis--2012: revision of the Atlanta classification and definitions by international consensus. Gut 2013;62:102-11.

27. US Food and Drug Administration. Guidance for industry: drug-induced liver injury-premarketing clinical evaluation. Available at http://www.fda gov/downloads/Drugs/.../Guidances/UCM174090.pdf, 2009. Accessed on 7 September 2016.

28. Shaffer EA. Gallbladder sludge: what is its clinical significance? Curr Gastroenterol Rep 2001;3:166-73.

29. Meleine M, Matricon J. Gender-related differences in irritable bowel syndrome: potential mechanisms of sex hormones. World J Gastroenterol 2014;20:6725-43.

30. Galligan JJ, Akbarali HI. Molecular physiology of enteric opioid receptors. Am J Gastroenterol 2014;2:17-21.

31. Howaizi M, Sbaï-Idrissi MS, Baillet P. Loperamide-induced acute pancreatitis. Gastroenterol Clin Biol 2000;24:589-91.
32. Vidarsdottir H, Vidarsdottir H, Moller PH et al. Loperamide-induced acute pancreatitis. Case Rep Gastrointest Med 2013;2013:517414.

33. Badalov N, Baradarian R, Iswara K et al. Drug-induced acute pancreatitis: an evidence-based review. Clin Gastroenterol Hepatol 2007;5:648-61.

34. Barreto SG, Tiong L, Williams R. Drug-induced acute pancreatitis in a cohort of 328 patients. A single-centre experience from Australia. JOP 2011;12:581-5.

35. Hastier P, Longo F, Buckley M et al. Pancreatitis induced by codeine: a case report with positive rechallenge. Gut 1997;41:705-6.

36. Hastier P, Buckley MJ, Peten EP et al. A new source of drug-induced acute pancreatitis: codeine. Am J Gastroenterol 2000;95:3295-8.

37. Trivedi CD, Pitchumoni CS. Drug-induced pancreatitis: an update. J Clin Gastroenterol 2005;39:709-16.

38. Turkmen S, Buyukhatipoglu H, Suner A et al. Prior cholecystectomy predisposes to acute pancreatitis in codeine-prescribed patients. Int J Crit Illn Inj Sci 2015;5:114-5.

39. Helm JF, Venu RP, Geenen JE et al. Effects of morphine on the human sphincter of Oddi. Gut 1988;29:1402-7.

40. Behar J, Biancani P. Neural control of the sphincter of Oddi. Physiologic role of enkephalins on the regulation of basal sphincter of Oddi motor activity in the cat. Gastroenterology 1984;86:134-41.

41. Thune A, Jivegård L, Pollard $\mathrm{H}$ et al. Location of enkephalinase and functional effects of [Leu5] enkephalin and inhibition of enkephalinase in the feline main pancreatic and bile duct sphincters. Clin Sci (Lond) 1992;82:169-73.

42. Patch GG, Morton KA, Arias JM et al. Naloxone reverses pattern of obstruction of the distal common bile duct induced by analgesic narcotics in hepatobiliary imaging. J Nucl Med 1991;32:1270-2.

43. Thompson DR. Narcotic analgesic effects on the sphincter of Oddi: a review of the data and therapeutic implications in treating pancreatitis. Am J Gastroenterol 2001;96:1266-72.

44. Steinberg WM, Salvato RF, Toskes PP. The morphine-prostigmin provocative test--is it useful for making clinical decisions? Gastroenterology 1980;78:728-31.

45. Mossberg SM, Bloom A, Berkowitz J et al. Serum enzyme activities following morphine. A study of transaminase and alkaline phosphatase levels in normal persons and those with gallbladder disease. Arch Intern Med 1962;109:429-37.

46. Roberts-Thomson IC, Pannall PR, Toouli J. Relationship between morphine responses and sphincter of Oddi motility in undefined biliary pain after cholecystectomy. J Gastroenterol Hepatol 1989;4:317-24.

47. Luman W, Williams AJK, Pryde A et al. Influence of cholecystectomy on sphincter of Oddi motility. Gut 1997;41:371-4.

48. US Food and Drug Administration. Viberzi. Highlights of prescribing information. Available at http://www.accessdata.fda.gov/drugsatfda_docs/ label/2015/206940s000lbl.pdf, 2015. Accessed on 17 July 2015.

49. Nathwani RA, Kumar SR, Reynolds TB et al. Marked elevation in serum transaminases: an atypical presentation of choledocholithiasis. Am J Gastroenterol 2005;100:295-8

50. Kagaya T, Takebe T, Koizumi M et al. Effect of long term alcohol feeding on the pancreas in rat. Gastroenterol Jpn 1979;14:327-35.

51. Pandol SJ, Raraty M. Pathobiology of alcoholic pancreatitis. Pancreatology 2007;7:105-14.

52. Shahedi K, Pandol SJ, Hu R. Oxidative stress and alcoholic pancreatitis. J Gastroenterol Hepatol Res 2013;2:335-42.

53. Guelrud M, Mendoza S, Rossiter G et al. Effect of local instillation of alcohol on sphincter of Oddi motor activity: combined ERCP and manometry study. Gastrointest Endosc 1991;37:428-32.

54. Viceconte G. Effects of ethanol on the sphincter of Oddi: an endoscopic manometric study. Gut 1983;24:20-27.

55. Kamm MA, Jordan CC, Leaker BR et al. Pharmacological modulation of gut mucosal and large vessel blood flow. Aliment Pharmacol Ther 2007;25:693-702.

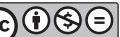

This work is licensed under a Creative Commons Attribution-NonCommercial-NoDerivs 4.0 International License. The images or other third party material in this article are included in the article's Creative Commons license, unless indicated otherwise in the credit line; if the material is not included under the Creative Commons license, users will need to obtain permission from the license holder to reproduce the material. To view a copy of this license, visit http://creativecommons.org/licenses/by-nc-nd/4.0/

(C) The Author(s) 2016 